\title{
REAÇÃO DE HÍBRIDOS SOMÁTICOS DE CITROS À INFECÇÃO POR Phytophthora nicotiana ${ }^{1}$
}

\author{
MEIRE MENEZES BASSAN², FRANCISCO DE ASSIS ALVES MOURÃO FILHO 3 , \\ BEATRIZ MADALENA JANUZZI MENDES ${ }^{4}$, BRUNO FORLI SCHWARTZ FREIRE ${ }^{5}$, \\ TATIANA EUGENIA CANTUARIAS-AVILÉS ${ }^{6}$, ANDRÉ BOLDRIN BELTRAME ${ }^{7}$
}

RESUMO - Este trabalho avaliou a resistência à infecção de tronco e de raízes por Phytophthora nicotianae em híbridos somáticos de citros com potencial para serem utilizados como porta-enxertos. Os híbridos somáticos avaliados foram laranja 'Hamlin' (Citrus sinensis) + toranja 'Indian Red' (Citrus grandis) (plantas 1 e 2) e laranja 'Hamlin' (C. sinensis) + toranja 'Singapura' (C. grandis). Plantas de limão 'Cravo' (Citrus limonia), laranja 'Caipira' (C. sinensis), laranja-azeda (C. aurantium) e Poncirus trifoliata 'Davis A' (Poncirus trifoliata) foram utilizadas como plantas-controle devido à reação conhecida à infecção pelo patógeno. Avaliações realizadas entre 30 e 60 dias após as inoculações com o patógeno incluíram o comprimento das lesões no tronco e a massa seca do sistema radicular nas plantas avaliadas. O híbrido somático laranja 'Hamlin' + toranja 'Indian Red' (planta 1) mostrou-se tolerante a P. nicotianae, indicando potencial para continuidade nas suas avaliações como porta-enxerto para citros.

Termos para indexação: gomose, laranja, melhoramento, porta-enxerto.

\section{REACTION OF CITRUS SOMATIC HYBRIDS TO THE INFECTION BY Phytophthora nicotianae}

\begin{abstract}
This study aimed to evaluate the resistance to trunk and root infection by Phytophthora nicotianae in citrus somatic hybrids with potential to be utilized as rootstocks. The somatic hybrids evaluated were 'Hamlin' sweet orange (Citrus sinensis) + 'Indian Red' pummelo (Citrus grandis) (plants 1 and 2), and 'Hamlin' sweet orange (C. sinensis) + 'Singapura' pummelo (C. grandis). Plants of 'Rangpur' lime (Citrus limonia), 'Caipira' sweet orange $(C$. sinensis), sour orange (C. aurantium), and Poncirus trifoliata 'Davis A' (Poncirus trifoliata) were used as control due to their known reaction to the pathogen. Evaluations were performed between 30 and 60 days after pathogen inoculation included the length of trunk lesions, and root dry mass of the root system of the evaluated plants. The somatic hybrid 'Hamlin' sweet orange + 'Indian Red' pummelo (plant 1) was tolerant to P. nicotianae, indicating potential to be further evaluated as a rootstock. Index terms: gummosis, improvement, orange, rootstock.
\end{abstract}

\section{INTRODUÇÃO}

Diversas doenças dos citros têm limitado a produtividade dos pomares comerciais. Aquelas causadas pelo gênero Phytophthora incluem a mais séria doença de solo nas plantas cítricas. No Brasil, as espécies Pytophthora nicotianae Breda de Haan (P. parasitica Dastur) e P. citrophthora são as mais frequentemente encontradas nas regiões citrícolas do País. No Estado de São Paulo, P. nicotianae é a espécie predominantemente associada às perdas mais significativas provocadas por esse patógeno, tanto em viveiros como em pomares comerciais (AMORIM, 1997).
Dentre as diversas doenças que podem ser causadas por esse patógeno, a podridão do colo e do tronco (gomose) e as podridões de raízes e radicelas são as manifestações mais relevantes nos pomares da doença causadas por Phytophthora spp. (FEICHTENBERGER, 2001). O controle das doenças ocasionadas por Phytophthora spp. incluem medidas curativas, como tratamento químico, controle biológico e cultural, e medidas preventivas, como utilização de mudas sadias e de porta-enxertos de espécies resistentes/tolerantes já existentes ou obtidas por programas de melhoramento genético.

\footnotetext{
1(Trabalho 145-09). Recebido em: 10-06-2009. Aceito para publicação em: 20-11-2009.

${ }^{2}$ Aluna de Graduação - USP/ESALQ, bolsista PIBIC/CNPq. meire.bassan@usp.br

${ }^{3} \mathrm{PhD}$ (Horticultural Sciences), Professor Associado. USP/ESALQ, Av. Pádua Dias, 11, Caixa Postal 9, 13418-900, Piracicaba-SP. Autor correspondente

${ }^{4}$ Doutora em Agronomia, Professora Associada. USP/Cena. mendes@cena.usp.br

${ }^{5}$ Aluno de Graduação - USP/ESALQ, bolsista Fundecitrus. brunofsfreire@uol.com.br

${ }^{6}$ Doutoranda em Fitotecnia - USP/ESALQ. tatiana.cantuarias@gmail.com

${ }^{7}$ Doutorando em Fitopatologia - USP/ESALQ. abbeltra@esalq.usp.br
} 
Devido ao aumento da incidência de problemas fitopatológicos na citricultura mundial, a incorporação de ferramentas biotecnológicas nos programas de melhoramento convencional dos citros pode facilitar o desenvolvimento de cultivares com características superiores (COSTA et al., 2003). Dentre essas técnicas, a hibridação somática permite combinar genitores com características complementares, sem perda significativa de vigor, resultando na expressão aditiva das características dominantes no híbrido. Possibilita, também, a transposição da incompatibilidade de cruzamentos entre espécies e gêneros. Consequentemente, novos genótipos potencialmente valiosos podem ampliar a base genética dos citros (MACHADO et al., 2005). Os porta-enxertos provenientes de hibridação somática têm demonstrado potencial na redução do tamanho da copa, aumento da tolerância a patógenos e incremento na qualidade dos frutos (GROSSER et al., 1998).

O objetivo deste trabalho foi avaliar a resistência à infecção de tronco e raízes por Phytophthora nicotianae de híbridos somáticos com potencial para serem utilizados como porta-enxertos.

\section{MATERIAL E MÉTODOS}

\section{Material vegetal}

Os híbridos somáticos laranja 'Hamlin' ( $\mathrm{C} i$ trus sinensis) + toranja 'Indian Red' (Citrus grandis) (plantas 1 e 2, com genótipo e fenótipo distintos) e laranja 'Hamlin' $(C$. sinensis $)+$ toranja 'Singapura' $(C$. grandis) (CALIXTO et al., 2004) foram propagados para avaliação da reação à Phytophthora nicotianae.

Estacas das plantas-matrizes dos híbridos somáticos foram induzidas ao enraizamento pela imersão em solução de ácido indolbutírico (AIB) na concentração de $1.000 \mathrm{mg} . \mathrm{L}^{-1}$, por $10 \mathrm{~min}$ e permaneceram em câmara de nebulização intermitente por aproximadamente 100 dias até o transplantio (PIO et al., 2006).

Plantas de limão 'Cravo' $(C$. limonia Osbeck), laranja 'Caipira' (C. sinensis), laranja-azeda ( $C$. aurantium) e Poncirus trifoliata 'Davis A' (Poncirus trifoliata), obtidas de sementes de frutos coletados da coleção de germoplasma de citros da USP/ESALQ, foram utilizadas como controle devido à reação conhecida aos patógenos estudados. As mudas e as estacas enraizadas foram transplantadas para sacos contendo substrato comercial (Rendmax Citrus ${ }^{\mathrm{TM}}$ ), suplementado com fertilizante de liberação lenta 22-04-08 (Osmocote ${ }^{\mathrm{TM}}$ ). As plantas foram mantidas em estufa telada, recebendo fertirrigações periódicas com a formulação 20-08-02 (Kristalon ${ }^{\mathrm{TM}}$ ).
Reação à infecção de tronco por Phytophthora nicotianae

Para a inoculação de $P$. nicotianae (isolado LRS 01/06) no tronco das plantas, as folhas foram removidas até a altura de $30 \mathrm{~cm}$, e a superfície do caule, desinfetada com álcool a 70\%. Foram realizadas duas inoculações por planta a 10 e $20 \mathrm{~cm}$ de altura, em posições opostas, demarcadas acima da região do colo para as plantas provenientes de sementes (controle), e acima da inserção da brotação da estaca, para os híbridos somáticos, utilizando-se o método da agulha (SIVIERO, 2001), cujos procedimentos para citros foram previamente descritos (MOURÃO FILHO et al., 2008). As avaliações foram realizadas 30 dias após as inoculações e incluíram: a) coleta e análise do comprimento da lesão sobre e sob a casca (na superfície do lenho, diretamente sobre a zona cambial); b) aumento relativo do comprimento das lesões em relação às plantas-controle (não inoculadas), calculado pela razão entre o valor do comprimento da lesão na planta infestada sobre o valor do comprimento da lesão na planta não infestada (não inoculada).

O delineamento experimental utilizado para inoculação do tronco foi o inteiramente casualizado, composto por sete tratamentos (três híbridos somáticos e quatro cultivares-controle), seis repetições, e unidade experimental constituída por duas plantas com duas inoculações por planta, totalizando 168 inoculações.

\section{ra nicotianae}

Reação à infecção de raizes por Phytophtho-

Para analisar a reação dos híbridos somáticos à infecção de raízes por Phytophthora nicotianae (isolado LRS 01/06), foi realizada a produção de inóculo para infestação de substrato e obtenção da suspensão de esporos, sendo empregado o método descrito por Ribeiro e Baumer (1977), modificado por Feichtenberger et al. (1984). Os procedimentos de preparo do material e inoculação em plantas cítricas foram previamente descritos (MOURÃO FILHO et al., 2008). As plantas foram irrigadas periodicamente após a inoculação, porém com volume controlado para não ocorrer escorrimento da água pelo fundo do saco plástico. A avaliação da severidade da doença foi realizada 60 dias após a inoculação e consistiu na análise da massa seca do sistema radicular das plantas experimentais.

$\mathrm{O}$ delineamento experimental utilizado foi o inteiramente casualizado, no esquema de parcela subdividida no espaço, com quatro repetições. As parcelas foram constituídas de plantas infestadas e 
plantas-controle, colocadas em bancadas separadas, representando o tratamento principal. Os sete genótipos (três híbridos somáticos e quatro cultivarescontrole) constituíram as subparcelas, representando o tratamento secundário, e foram distribuídas ao acaso nas parcelas. Cada subparcela foi composta de duas plantas, em um total de 14 plantas-controle e 14 plantas infestadas, totalizando 28 plantas.

\section{RESULTADOS E DISCUSSÃO}

\section{Reação à infecção de tronco por Phyto- phthora nicotianae}

Trinta dias após a inoculação do micélio de Phytophthora nicotianae no caule dos porta-enxertos e híbridos somáticos, as lesões ocasionadas nas plantas foram quantificadas. Nas plantas-controle, nas quais as incisões foram causadas apenas com a agulha e água destilada, ocorreu a formação de uma cicatriz no local da lesão, a qual é caracterizada pela hiperplasia de células da planta em torno do ferimento, na tentativa de regenerar o tecido afetado (SALGADO;AMORIM, 1995).

A variável adotada para avaliar a resistência às infecções de tronco foi o comprimento das lesões sob e sobre a casca. Trabalhos anteriores indicaram que a utilização de medidas de comprimento das lesões é mais apropriada na classificação de resistência de porta-enxertos e novos genótipos em relação a Phytophthora spp., quando comparadas com medidas de largura (SIVIERO, 2001).

Neste experimento, foram realizadas duas lesões por caule, em posições inferior e superior, sendo que a média destas foi utilizada para análises e considerações subsequentes. Medina et al. (2003), inoculando artificialmente em duas posições do tronco 132 plantas nucelares dos genitores e 486 híbridos entre limão Cravo 'Limeira' (Citrus limonia), Poncirus trifoliata 'Davis A', tangerina 'Sunki' (C. sunki) e laranja-azeda 'São Paulo' (C. aurantium) observaram não haver diferença significativa entre as posições de inoculação no desenvolvimento das lesões.

Com relação à análise do comprimento das lesões sobre e sob a casca dos porta-enxertos e híbridos somáticos, houve diferença entre os genótipos estudados (Tabela 1). Entretanto, Pio (2005), ao verificar possíveis resistências/tolerâncias à infecção de tronco por Phytophthora nicotianae pela mesma metodologia, constatou que o resultado entre as áreas e os comprimentos da lesão sob a casca foi semelhante, evidenciando que a medida do comprimento da lesão sob a casca é a forma mais adequada para quantificar a podridão do colo ocasionada por Phytophthora nicotianae.
Dessa forma, verifica-se que os genótipos mais resistentes são Poncirus trifoliata e laranjaazeda, uma vez que estes apresentaram menores comprimentos de lesão sob a casca em relação aos outros genótipos (Tabela 1). O limão 'Cravo' não apresentou diferença significativa em relação à laranja-azeda para esta variável. O mesmo ocorreu com o híbrido somático laranja 'Hamlin' + toranja 'Indian Red' (planta 1) em relação ao limão 'Cravo'.

Os resultados encontrados em relação aos porta-enxertos conhecidos estão de acordo com os relatados em outros trabalhos, em que o Poncirus trifoliata foi classificado como altamente resistente, a laranja-azeda como resistente, o limão 'Cravo' como moderadamente resistente e a laranja 'Caipira' como suscetível (PIO, 2005; SIVIERO et al., 2002). Os resultados obtidos sobre a resistência/ suscetibilidade dos porta-enxertos em campo, citados em outras pesquisas (FEICHTENBERGER, 2001), estão em concordância com as reações encontradas nas observações e dados coletados neste trabalho.

Ao avaliar o aumento do comprimento das lesões das plantas infectadas em relação às plantascontrole, Poncirus trifoliata mostrou-se o genótipo mais resistente, apresentando a menor relação de aumento das lesões, enquanto os híbridos somáticos apresentaram aumento de aproximadamente três vezes, mostrando-se, dessa forma, menos resistentes às infecções do tronco causadas por Phytophthora nicotianae (Tabela 1).

Os híbridos somáticos que apresentaram menor resistência ao desenvolvimento de lesões causadas pelo inóculo, foram laranja 'Hamlin' + toranja 'Indian Red' (planta 2) e laranja 'Hamlin' + toranja 'Singapura', sendo este último o genótipo que apresentou as maiores lesões (Tabela 1). O híbrido somático laranja 'Hamlin' + toranja 'Indian Red' (planta 1) apresentou o melhor resultado entre os híbridos somáticos avaliados, com médias semelhantes às do limão 'Cravo', que é moderadamente resistente.

A laranja 'Hamlin' é caracterizada por apresentar altas produtividades, porém não é usada como porta-enxerto, pois é muito suscetível a Phytophthora spp. (LOUZADA et al., 1992). As toranjas apresentam tolerância a doenças induzidas por Phytophthora spp., além de tolerar estresse salino e altos valores de $\mathrm{pH}$ do solo (MOORE et al., 2000). Portanto, o desenvolvimento desses híbridos somáticos tem como propósito poderem ser utilizados em programas de melhoramento de citros como porta-enxertos resistentes a doenças induzidas por Phytophthora spp., além de apresentar uma progênie altamente nucelar através da complementaridade 
das características dos genitores (CALIXTO et al., 2004). Avaliações adicionais sobre a tolerância dos híbridos somáticos ao vírus da tristeza dos citros (CTV) utilizados neste experimento indicaram que os mesmos podem ser considerados tolerantes a este patógeno (dados não apresentados).

Analisando os resultados obtidos, verifica-se que os genótipos dos híbridos somáticos diferiram de forma significativa entre si, o que pode estar relacionado às diferentes origens das toranjas utilizadas, uma vez que a planta de 'Indian Red' era enxertada, e a 'Singapura', um seedling derivado de frutos daquela cultivar (CALIXTO et al., 2004).

Como a hibridação somática é um processo em que não existe segregação meiótica, resultando na expressão aditiva das características dominantes nos híbridos, genes deletérios recessivos em genitores sob uma condição heterozigota, provavelmente, permanecerão não expressos nos híbridos somáticos, e características controladas por genes dominantes ou co-dominantes, em um dos genitores, terão grande probabilidade de se expressar no híbrido somático (GROSSER;GMITTER JUNIOR, 1990). Desta forma, as características de resistência esperadas nos híbridos somáticos podem não estar presentes devido à possibilidade de estas serem controladas por genes recessivos. Resultados semelhantes foram obtidos por Pio (2005) com o híbrido tangerina 'Cleópatra' + laranja-azeda, que não diferiu da laranja-azeda para a presença de goma, diferindo-se, porém, da tangerina 'Cleópatra'.

\section{ra nicotianae}

Reação à infecção de raizes por Phytophtho-

Sessenta dias após a infestação do substrato com esporos e clamidósporos de Phytophthora nicotianae, a massa seca das raízes das plantas-controle e infestadas foram pesadas, indicando que não houve diferença para nenhum dos genótipos estudados (Tabela 2). Resultados semelhantes foram encontrados por Pio (2005) para os porta-enxertos laranja-azeda e Poncirus trifoliata. Entretanto, para laranja 'Caipira' e limão 'Cravo', o mesmo autor verificou que houve diferença entre as plantas-controle e infestadas.

Com relação ao Poncirus trifoliata, os resultados concordam com o de trabalhos anteriores (MEDINA FILHO et al., 2004; PIO, 2005; GRAHAM, 1995), confirmando sua alta resistência em relação à infestação das raízes com Phytophthora spp. Quanto à laranja-azeda, têm sido publicados relatos bastante divergentes com relação à sua classificação, devido ao fato de esta apresentar diversos clones distintos. Os resultados observados concordam com Pio (2005), porém discordam de outras pesquisas
(GRIMM; HUTCHISON, 1973; MEDINA FILHO et al., 2004; GRAHAM, 1990, 1995), que encontraram reduções significativas na massa das raízes quando estas foram infestadas com Phytophthora spp. e classificaram-na como pouco tolerante à podridão de raízes. Logo, é possível que essa divergência de resultados encontrados sobre seu comportamento quanto à Phytophthora spp. se deva à diversidade genética de seus clones.

O limão 'Cravo' não apresentou reduções significativas na massa de raízes quando estas foram infestadas por Phytophthora spp., embora estudos desenvolvidos por Pio (2005) e Medina Filho et al. (2004) mostrarem o contrário, de forma que este porta-enxerto é classificado como moderadamente tolerante quanto à podridão das raízes e radicelas ocasionada por Phytophthora nicotianae (PIO, 2005).

Resultados controversos também foram encontrados para o porta-enxerto laranja 'Caipira', pois, no presente estudo, as plantas infestadas não diferiram dos controles. Estes resultados discordam da literatura, pois laranjas-doces em geral são classificadas como altamente suscetíveis à podridão de raízes causadas por Phytophthora spp. (PIO, 2005; GRAHAM, 1990, 1995).

Com relação aos híbridos somáticos avaliados, verificou-se que as três combinações estudadas apresentaram resistência à podridão de raízes causadas por Phytophthora nicotianae, pois não houve diferenças entre os valores massa seca média das raízes nas plantas-controle e infestadas (Tabela 2). Estes resultados estão de acordo com o esperado, pois a hibridação somática via fusão de protoplastos objetiva produzir híbridos alotetraploides, em que os híbridos produzidos possuem genes de ambos os genitores, somando as características horticulturais desejáveis (GROSSER; GMITTER JUNIOR, 1990). Devido ao fato de as plantas de laranja-azeda também não terem apresentado diferenças entre plantas infestadas e não infestadas para massa seca média das raízes, experimentos adicionais devem ser realizados para a confirmação destes resultados.

Vale ressaltar que todas as espécies cítricas são capazes de ter suas raízes e radicelas infectadas por $P$. nicotianae (GRAHAM, 1990), inclusive plantas de Poncirus trifoliata ('Davis A'e 'Rich 6-16'), consideradas como altamente tolerantes. Assim, a tolerância do porta-enxerto está relacionada diretamente à sua capacidade de emitir novas raízes e radicelas frente ao ataque do patógeno no solo (GRAHAM, 1995). Este fato pode ser relacionado aos híbridos somáticos estudados, já que estes apresentaram maior massa seca média das plantas infestadas quando comparadas com as controle. 
Relacionando-se os resultados obtidos, embora os híbridos somáticos 'Hamlin' + toranja 'Indian Red' (planta 2) e laranja 'Hamlin' + toranja 'Singapura' tenham-se apresentado tolerantes à podridão de raízes, não apresentaram os mesmos resultados em relação à infecção no tronco. Dessa forma, observase que nem sempre há boa relação entre a resistência às infecções de tronco e a tolerância às podridões de raízes por Phytophthora spp., não devendo assim analisar novos genótipos de citros apenas pelas suas reações a infecções do tronco e sim, também, pelas suas respostas à podridão das raízes e radicelas, visando a obter informações quanto ao comportamento dos genótipos frente a essas duas doenças importantes ocasionadas por Phytophthora spp..

A utilização da resistência genética como método de controle é a forma que menos onera o produtor e é a base da exploração das principais plantas cultivadas. Dessa forma, o uso de porta-enxertos resistentes constitui-se na medida mais importante de controle das podridões do colo provocadas por Phytophthora spp. (FEICHTENBERGER, 1990; 1996). Para a escolha de um porta-enxerto, é recomendado que este apresente, pelo menos, moderada resistência a Phytophthora spp. Desta forma, o híbrido somático laranja 'Hamlin' + toranja 'Indian Red' (planta 1) merece destaque, já que é semelhante ao limão 'Cravo', considerado moderadamente resistente, apresentando, dessa forma, potencial para ser utilizado em programas de melhoramento de citros ou diretamente como porta-enxerto após avaliações horticulturais em plantas enxertadas no campo.

TABELA 1- Comprimento das lesões e aumento relativo do comprimento das lesões sobre e sob a casca, ocasionadas por inoculações de Phytophthora nicotianae, em caules de porta-enxertos e híbridos somáticos de citros. Piracicaba-SP, 2008.

\begin{tabular}{|c|c|c|c|c|}
\hline \multirow[t]{3}{*}{ Genótipos } & \multicolumn{4}{|c|}{ Comprimento* } \\
\hline & Sob a casca & Sobre a casca & Sob a casca & Sobre a casca \\
\hline & \multicolumn{2}{|c|}{------------mm--------- } & \multicolumn{2}{|c|}{------------vezes---------- } \\
\hline Poncirus trifoliata & $4,95 \mathrm{~A}^{* *}$ & $5,54 \mathrm{AB}$ & 1,54 & 1,38 \\
\hline Laranja-azeda & $7,75 \mathrm{AB}$ & $4,40 \mathrm{~A}$ & 1,65 & 1,25 \\
\hline Limão 'Cravo' & $8,90 \mathrm{~B}$ & $7,33 \mathrm{BC}$ & 2,43 & 1,35 \\
\hline Laranja 'Hamlin' + toranja 'Indian Red' (1) & $9,44 \mathrm{BC}$ & $8,59 \mathrm{C}$ & 2,67 & 1,74 \\
\hline Laranja 'Hamlin' + toranja 'Indian Red' (2) & $12,11 \mathrm{CD}$ & $8,73 \mathrm{C}$ & 2,98 & 1,96 \\
\hline Laranja 'Caipira' & $12,51 \mathrm{CD}$ & $9,67 \mathrm{CD}$ & 3,22 & 1,62 \\
\hline Laranja 'Hamlin' + toranja 'Singapura' & $13,95 \mathrm{D}$ & $12,05 \mathrm{D}$ & 3,31 & 1,61 \\
\hline CV (\%) & \multicolumn{2}{|c|}{15,32} & \multicolumn{2}{|r|}{ - } \\
\hline
\end{tabular}

*Valores correspondem à média de 2 lesões por planta, sendo um total de 12 plantas avaliadas por genótipo.

** Médias seguidas da mesma letra na coluna não diferem significativamente entre si, pelo teste de Tukey, ao nível de 5\% de probabilidade.

TABELA 2- Massa seca média das raízes de porta-enxertos e híbridos somáticos de citros, cultivados em substrato com e sem Phytophthora nicotianae, comparando-se plantas-controle (C) e infestadas (I), ao final de 60 dias. Piracicaba-SP, 2008.

\begin{tabular}{|c|c|c|}
\hline \multirow[t]{2}{*}{ Genótipos } & \multicolumn{2}{|c|}{ Massa seca das raízes } \\
\hline & Controle & Infestadas \\
\hline & \multicolumn{2}{|c|}{------------g---------- } \\
\hline Poncirus trifoliata & $13,96 \mathrm{~A}^{*}$ & $14,51 \mathrm{~A}$ \\
\hline Limão ‘Cravo’ & $33,49 \mathrm{~A}$ & $29,97 \mathrm{~A}$ \\
\hline Laranja-azeda & $33,38 \mathrm{~A}$ & $28,45 \mathrm{~A}$ \\
\hline Laranja 'Hamlin' + toranja 'Singapura' & $12,58 \mathrm{~A}$ & $14,42 \mathrm{~A}$ \\
\hline Laranja 'Caipira' & $19,57 \mathrm{~A}$ & $25,77 \mathrm{~A}$ \\
\hline Laranja 'Hamlin' + toranja 'Indian Red' (2) & $5,33 \mathrm{~A}$ & $5,34 \mathrm{~A}$ \\
\hline Laranja 'Hamlin' + toranja 'Indian Red' (1) & $6,05 \mathrm{~A}$ & $8,59 \mathrm{~A}$ \\
\hline $\mathrm{CV}(\%)$ & \multicolumn{2}{|c|}{21,13} \\
\hline
\end{tabular}

Médias seguidas da mesma letra na linha não diferem significativamente entre si, pelo teste de Tukey, ao nível de $5 \%$ de probabilidade. 


\section{CONCLUSÃO}

O híbrido somático laranja 'Hamlin' + toranja 'Indian Red' (planta 1) apresenta resistência satisfatória à infecção de tronco e podridão de raízes causadas por Phytophthora nicotianae. Portanto, é um genótipo com potencial para ser explorado em programas de melhoramento genético de citros para porta-enxerto ou diretamente como porta-enxerto após avaliações horticulturais em plantas enxertadas no campo.

\section{AGRADECIMENTOS}

Os autores agradecem ao Fundo de Defesa da Citricultura (Fundecitrus), pelo apoio financeiro; a primeira autora agradece ao CNPq, pela bolsa de Iniciação Científica; o segundo e terceiro autores agradecem ao $\mathrm{CNPq}$, pela bolsa de produtividade em pesquisa; os autores agradecem ao Pesquisador Eduardo Feichtenberger (Unidade de Pesquisa e Desenvolvimento de Sorocaba, APTA Regional), pelo fornecimento do isolado de Phytophthora nicotianae utilizado no experimento.

\section{REFERÊNCIAS}

AMORIM, E.P.R. Controle biológico de Phytophthora nicotianae var. parasitica Dastur e Phytophthora citrophthora (Smith \& Smith) Leonian em plântulas de citros. 1997. 111 f. Tese (Doutorado) - Faculdade de Ciências Agronômicas, Universidade Estadual Paulista, Botucatu, 1997.

CALIXTO, M.C.; MOURÃO FILHO, F.A.A.; MENDES, B.M.J.; VIEIRA, M.L.C. Somatic hybridization between Citrus sinensis (L.) Osbeck and C. grandis (L.) Osbeck. Pesquisa Agropecuária Brasileira, Brasília, v.39, p.721-724, 2004.

COSTA, M.A.P.C.; MENDES, B.M.J.; MOURÃO FILHO, F.A.A. Somatic hybridisation for improvement of citrus rootstock: production of five new combinations with potential for improved disease resistance. Australian Journal of Experimental Agriculture, Melbourne, v.43, p.1151-1156, 2003.

FEICHTENBERGER, E. Doenças incitadas por Phytophthora em citros. In: LUZ, E.D.M.N.; SANTOS, A.F. dos; MUTSUOKA, K.; BEZERRA, J.L. Doenças causadas por Phytophthora no Brasil. Campinas: Livraria Editora Rural, 2001. p. 283-342. dos citros. Laranja, Cordeirópolis, v.11, p.97-122, 1990.

FEICHTENBERGER, E. Manejo ecológico de gomose de Phytophthora dos citros. São Paulo: Rhodia Agro, 1996. 41p.

FEICHTENBERGER, E.; ZENTMEYER, G.A.; MENGE, J.A. Identify of Phytophthora isolated from milkweed vine. Phytopathology, Saint Paul, v.17, p.50-55, 1984.

GRAHAM, J.H. Evaluation of tolerance of citrus rootstocks to Phytophthora root rot in chlamydospore-infested soil. Plant Disease, St Paul, v.74, p.743-746, 1990.

GRAHAM, J.H. Root regeneration and tolerance of citrus rootstocks to root rot caused by Phytophthora nicotianae. Phytopathology, St Paul, v.85, n.1, p.111-117, 1995.

GRIMM, G.R.; HUTCHISON, D.J. A procedure for evaluating resistance of citrus seedlings to Phytophthora parasitica. Plant Disease, St Paul, v.57, n.8, p.669-672, 1973.

GROSSER, J.W.; GMITTER JUNIOR, F.G. Somatic hybridization of Citrus with wild relatives for germplasm enhancement and cultivar development. HortScience, Alexandria, v.25, n.2, p.147-151, 1990.

GROSSER, J.W.; GMITTER JUNIOR, F.G.; CASTLE, W.S.; CHANDLER, J.L. Somatic hybridization: a new approach to citrus rootstock improvement, Fruits, Paris, v.53, n.5, p331-334, 1998.

LOUZADA, E.S.; GROSSER, J.W.; GMITTER JUNIOR, F.G.; NIELSEN, B.; CHANDLER, J.L. Eight new somatic hybrid citrus rootstock with potential for improved disease resistence. HortScience, Alexandria, v.27, p.1033-1036, 1992.

MACHADO, M.A.; CRISTOFANI, M.; AMARAL, A.M. do; OLIVEIRA, A.C. Genética, melhoramento e biotecnologia de citros. In: MATTOS JUNIOR, D.; NEGRI, J.D.; PIO, R.M.; POMPEU JÚNIOR, J. Citros. Campinas: Instituto Agronômico; Fundag, 2005. p. 243-246.

MEDINA FILHO, H.P.; BORDIGNON, R.; SIQUEIRA, W.J.; FEICHTENBERGER,E.; CARVALHO, M.R.T. Tolerância de híbridos e de clones

FEICHTENBERGER, E. Gomose de Phytophthora 
de porta-enxertos de citros à infecção de raízes por Phytophthora nicotianae. Fitopatologia Brasileira, Brasília, v.29, n.2, p.169-178, 2004.

MEDINA FILHO, H.P.; BORDIGNON, R.; SIQUEIRA, W.J.; FEICHTENBERGER, E.; CARVALHO, M.R.T.; TEÓFILO SOBRINHO, J. Resistência de clones e híbridos de porta-enxertos de citros à gomose de tronco causada por Phytophthora parasitica. Fitopatologia Brasileira, Brasília, v.28, n.5, p.534-540, 2003.

MOORE, G.A.; GUY, C.L.; TOZLU, I.; WEBER, C.A. Mapping quantitative trait loci for salt tolerance and cold tolerance in Citrus grandis (L.) Osb. $\mathrm{x}$ Poncirus trifoliata (L.) Raf. hybrid populations. Acta Horticulturae, The Hague, v.535, p.37-45, 2000.

MOURÃO FILHO, F.A.A.; PIO, R.; MENDES, B.M.J.; AZEVEDO, F.A.; SCHINOR, E.H.; ENTELMANN, F.A.; ALVES, A.S.R.; CANTUÁRIASAVILES. Evaluation of citrus somatic hybrids for tolerance to Phytophthora nicotianae and citrus tristeza virus. Scientia Horticulturae, Amsterdam, v.115, p.301-308, 2008.

PIO, R. Propagação de híbridos somáticos de citros e reação à infecção por Phytophthora nicotianae e vírus da tristeza dos citros. 2005. $144 \mathrm{f}$. Tese (Doutorado) - Escola Superior de Agricultura "Luiz de Queiroz", Universidade de São Paulo, Piracicaba, 2005.

PIO, R.; MOURÃO FILHO, F. de A.A.; MENDES, B.M.J.; ENTELMANN, F.A.; ALVES, A.S.R. Propagation of citrus somatic hybrids with potential for utilization as rootstocks. Fruits, Paris, v.61, p.1-7, 2006.

RIBEIRO, O.K.; BAUMER, J.S. Techniques for sporangia production of Phytophthora megasperma isolates. Phytophthora Newsletter, Bangor, v.5, p.42-43, 1977.

SALGADO, C.L.; AMORIM, L. Sintomatologia. In: BERGAMIM FILHO, A.; KIMATI, H.; AMORIM, L. (Ed.). Manual de fitopatologia: princípios e conceitos. São Paulo: Ceres, 1995. v.1, p.212-223.

SIVIERO, A. Avaliação de métodos de inoculação de Phytophthora parasitica e mapeamento de QTLs de resistência em híbridos de Citrus sunki $\boldsymbol{x}$ Poncirus trifoliata à gomose. 2001. $114 \mathrm{f}$. Tese (Doutorado) - Faculdade de Ciências Agronômicas, Universidade Estadual Paulista, Botucatu, 2001.

SIVIERO, A.; FURTADO, E.L.; BOAVA, L.P.; BARBASSO, D.V.; MACHADO, M.A. Avaliação de métodos de inoculação de Phytophthora parasitica em plântulas e plantas jovens de citros. Fitopatologia Brasileira, Brasília, v.27, n.6, p. 574-580, 2002. 